\title{
The Approaches to the Classification of Enterprise Sustainability Factors
}

Diana Sergeevna Kandaurova

Samara State University of Economics, Russia, 443090, Samara, Sovetskoi Armii Street,141

Svetlana Igorevna Ashmarina

Samara State University of Economics, Russia, 443090, Samara, Sovetskoi Armii Street,141

Anna Sergeevna Zotova

Samara State University of Economics, Russia, 443090, Samara, Sovetskoi Armii Street,141

Email: azotova@mail.ru

\section{Doi:10.5901/mjss.2015.v6n3p247}

\section{Abstract}

The reforms which are carried out in economic system of Russia and around the world, the fastening speed of globalization processes resulting in the processes of international market generation influence greatly the trends and the essence of development stages of national industrial enterprises. The priority of Russian enterprises development has been given to the matters of production structure, the matters of supply and demand in the markets of human resources, educational services, scientific research and development. But the prior matter is optimization process of industrial enterprise activity for their sustainable development in long-term period. The first step here is to analyze the main factors that may influence industrial enterprise sustainability. This task stipulates the goal of the research work presented in the article.

Keywords: sustainable development; sustainability factors; external environment; development potential.

\section{Introduction}

\subsection{Background}

The basic principles of the external environment assessment were set out in the research works where the whole environment was divided into macro level environment systems and the micro level which can be influenced by the enterprise. (Porter M., 2004) The groups of organization stakeholders are usually formed from the system of microenvironment and they define the enterprise policy according to their own interests, so the matters of relationship of the enterprise and its stakeholders are also thoroughly studied. (Sokolova Y., 2013)

The possibility of the enterprise to move in the direction of the set goal keeping its stable position at the market and possibility to develop even under the condition of unfavorable influence of some factors is understood as sustainable development. The concept of sustainable economic development was studied thoroughly and the result of the study was the idea that the aims of environment protection and economic development do not contradict (Barbier E., 1987). Some research work has been done in order to find out how the corporation can achieve sustainability and what changes should be implemented in it for this aim (Dyllick, T.,Hockerts, K. 2002; Doppelt B., 2003; Dunphy, D., 2007).

\subsection{Status of the problem}

The sustainable development of the enterprise is characterized by the great number of factors. Their diversity, the absence of reliable system of their evaluation and the absence of possibility to make forecasts about some of them may lead to negative consequences for enterprise sustainable development. The research is planned to be the one that gives the grounds for trends and criteria of factor systematization. This research is also aimed at the study of international experience and Russian practices in order to formulate the principles, the basic and specific characteristics of sustainability model design both for separate industrial enterprises and for the whole industrial economy of the Russian Federation. The aim is to give the basis for future grounds for change implementation from the sustainability approach 
and adjustment of interests of industrial enterprises and social and economic systems of different levels starting from the study of peculiar sustainability factors and classifying them.

\section{External Environment Factor Analysis}

Taking the existing research works of the theory and practice of economic systems sustainable development the authors defined meaningful groups of factors that influence sustainable development greatly.

The factors of the external environment can be subdivided into two groups the factors of direct influence and the factors of indirect influence.

The environment of direct influence is the element of the environment which affects the enterprise immediately and specifically. The most dynamic among them are consumers and competitors. The consumers of the enterprise determine the demand at the market and as P. Drucker (1980) said "the only aim of each business is to generate the consumer". So the possibility of enterprise creation, its future activity and development is under direct dependence of the enterprise ability to attract the consumer and gain its respect. Another important factor of the enterprise development is competitiveness. The competitive struggle can greatly influence the internal environment of the enterprise especially the production organization process. That is why nowadays it is extremely important to raise the competitiveness of the produced goods in order to support not only the current existence of the enterprise but also its development. The suppliers as the external factor can support the efficient entrance of the system to the market by rhythmic and just-in-time delivery of production means, resources and materials including economy, information, energy, staff and other resources. This elements demands constant changes in the negotiations policy. Contact audience is the factor that forms the attitude of financial structures, regional state administration, mass media towards the enterprise.

The reaction of the enterprise at the transformation of the direct influence factors can be dual. It can change the inner structure of the organization in order to implement adjustment policy or it can mobilize all its resources and make an effort to implement contraction policy (either active or passive).

The environment of indirect influence includes the factors that do not influence immediately and directly but their impact should be taken into account. The economic entity may only adapt to such factors but cannot change them. The factors of this level may give opportunities and may also constrain the enterprise activity. Political situation affects the enterprise development greatly because the investment inflow of the country and the opening of external markets for domestic goods depends on it. Economy situation can influence the enterprise through the economy development phases. The quotation of domestic enterprises securities at the stock exchange, the prices for energy resources, national currency exchange rate, inflation level, interest payments for credits are the factors that reflect the condition of national economy. And if the economy is at its raising phase it affects positively the activity and development of the enterprises. Other influential factors of the indirect influence are scientific and technology progress, information supply, social and cultural factors, the global market, ecology factors.

The description, analysis and possibility to forecast the influence of the indirect factors is rather difficult and timeconsuming process. It is rather difficult to formalize such factors because they cannot be evaluated from the point of quantitative characteristics but it should be taken into account that in some periods of humanity development characterized by the changes in society economy structure the role of these factors may increase.

\section{Internal Environment Factor Analysis}

The internal environment is some definite interconnection of composite elements affecting directly the process of resource flows transformation into the flows of products. According to the functional subsystems the following factors can be highlighted.

Production - is a complex process which can be characterized by the applied equipment, technology, staff qualification. The quality of produced goods is directly dependable on the excellence of equipment and technologies and thus they influence the competitiveness of the organization (Ghemawat, $P, 1999$ ).

Finance. The process of financial resources planning influence the possibility to attract investment, circulating assets renewal, the use of the gained profit and the whole development of the enterprise.

Marketing is the instrument which helps to raise the foundation and logic of decisions made about production and sale policy, about financial and economic policy, about scientific and technology policy.

Staff is one of the main resources of the enterprise and its functioning is impossible without this resource. Staff qualification, its motivation incentives affect directly economic entities sustainability.

Innovation characterizes the enterprise inner environment which can either help its development or be an obstacle 
in the way to sustainability. Innovation activity is a complex dynamic system of action and interaction of different managerial methods, factors and structures.

Management of the enterprise lies in production and economic activity organization directed at sustainable development which is determined by definite flexibility of applied management methods, sensible distribution of production flows, right application of material resources, professional production process management, adaptable organization structure and management system, stable information supply.

According to the sustainability degree of enterprise functional subsystems the following factors can be indicated.

Production sustainability is characterized by optimum production elements usage, the high level of production organization, constant control over production efficiency improvement.

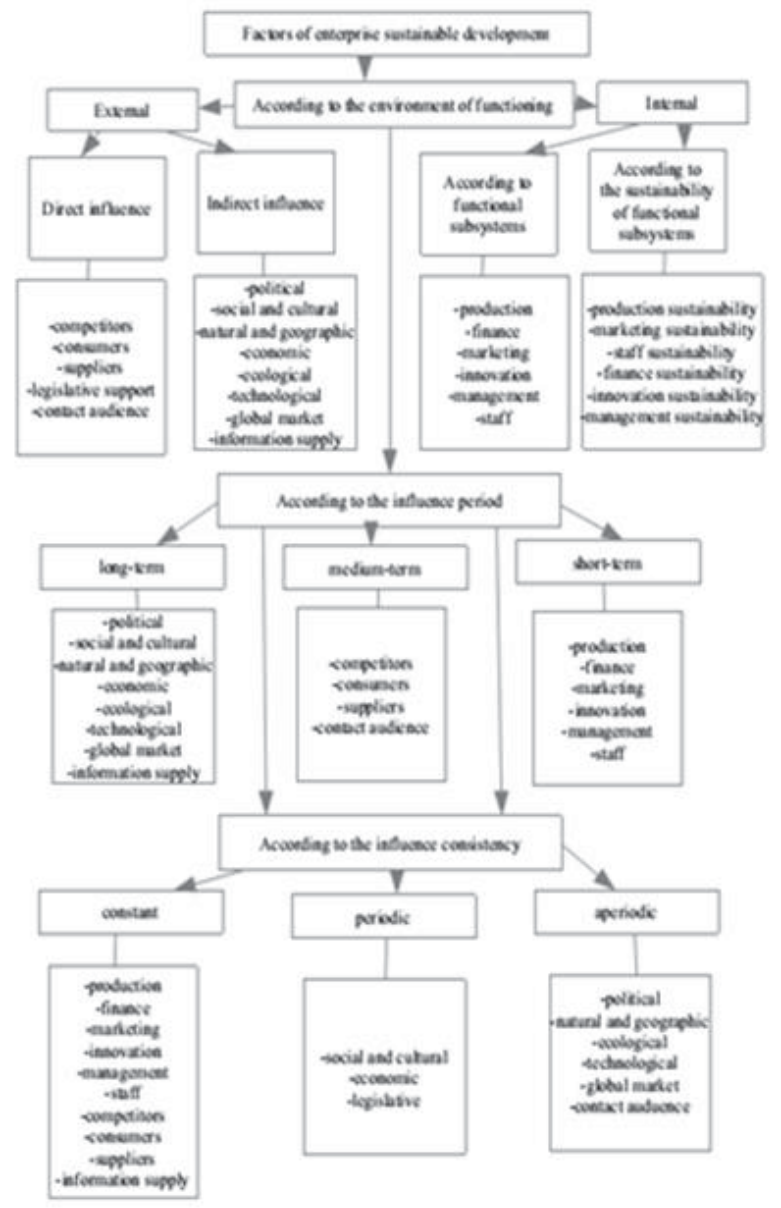

Figure 1. The classification of sustainable development factors of an industrial enterprise.

Production sustainability gives understanding of production management quality, it also affects labour productivity, the quality of after-sale services, work standardization level improvement.

Financial sustainability is determined by the elaborated strategy of the enterprise, financial plans working out, the definition of financing sources, financial structures and departments coordination. Financial sustainability is characterized by the ability of the industrial enterprise to keep the planned level of profitability and paying capacity for the long-term period. More than that the financial sustainability allows to optimize the basic financial indicators which influence on the changes in economic condition of the enterprise, allows to find out all available sources of material resources and evaluate the necessity of their attraction for gaining the profit.

Marketing sustainability reflects the complex of marketing strategies which are directed at enterprise aims implementation. Specifically these aims are to get accurate and objective information about the demand at various segments of the market, to decrease the risk of irregularity of orders, to increase plant capacity usage and to increase the 
enterprise rating.

Staff sustainability is characterized by staff qualification, its initiative, communicability, the level of organization culture, the existing motivation and incentives system.

Innovation sustainability is continuous work of creating and applying improved technological products and the ways of making business activity.

Management sustainability is characterized by the existence of efficiently organized management structure, inner coordination, regulated interconnection between the departments, ability of fast reaction to the changes.

The functioning of the enterprise nowadays is performed in the condition of constant rise of complexity and uncertainty of the exterior and interior environment. This is becoming one of the key problems for continuous and sustainable growth of enterprises. Contemporary managers have to make decisions under the conditions when the product life-cycle grows short, the production profitability falls, the technology systems change systematically. That is why the effective management of internal elements allows to minimize the external influence and support the continuous movement to the sustainable development. According to the stability of influence the authors defined the factors of constant influence such as consumers, suppliers, competitors, staff, production, marketing, innovation, information supply and management factors. The factors of periodic influence such as economy, legislation or culture factors. Aperiodic factors include political, technical, international, ecological influence and the influence of contact audience.

Taking the approaches to the sustainability factor analysis the authors elaborated the detailed classification of sustainable development factors (Figure 1).

\section{Conclusion}

The research work allows to perform the following basic ideas:

At first, the enterprise is the open system and can function effectively only under the condition of interconnection with the external environment. The factors of external environment allow to develop, to gain profit and to meet the consumers interests.

At second, the detailed and systematic internal and external factor classification helps to state the influence of each factor on the enterprise effectiveness.

At third, the importance of external factors raises with the increase of the environment complexity because of the globalization process of social and economic relationship in the society.

At fourth, the indication and definition of internal environment factors allows to study the limits of production and sale abilities of the enterprise and to find out the necessary growth reserves and change trends which help to achieve the maximum effect for the long-term period.

At fifth, the study of theoretical foundation of the industrial enterprise sustainable development showed the necessity of further research in the sphere of sustainable development management in order to elaborate the basic principles and methods of industrial enterprise sustainability management.

\section{Acknowledgments}

The authors thank all participants of the study for their kind cooperation.

\section{References}

Barbier E.(1987) The Concept of Sustainable Economic Development. Environmental Conservation 14 (2): 101-110

Doppelt B. (2003) Leading change towards sustainability:A Change-Management Guide for Business, Government, and Civil Society. Greenleaf Publishing.

Drucker P. (1980) Managing in Turbulent Times. New York: Harper \& Row.

Dunphy, D., Griffiths, A., Benn, S. (2007) Organizational Change for Corporate Sustainability. 2nd ed. Routledge Lon NY.

Dyllick T., Hockerts, K. (2002) Beyond the business case for corporate sustainability. Business Strategy and the Environment, 11(2): 130-141.

Ghemawat, P. (1999) Strategy and the Business Landscape. Addison-Wesley.

Porter M.E. (2004) Competitive advantage: creating and sustaining superior performance. New York: Free Press.

Sokolova Y.A. (2013) The Board and stakeholders: interests and contradictions. The Matters of Economy Sciences,1, 21-25 